\title{
Unresectable Skin Basal Cell Carcinoma
}

National Cancer Institute

\section{Source}

National Cancer Institute. Unresectable Skin Basal Cell Carcinoma. NCI Thesaurus. Code C157331.

Basal cell carcinoma of the skin that is not amenable to surgical resection. 